\title{
Differential Subcellular Responses in Resistance Soybeans Infected with Soybean Cyst Nematode Races
}

\author{
Young Ho Kim ${ }^{1 *}$, Kyung Soo Kim ${ }^{2}$ and Robert D. Riggs ${ }^{2}$ \\ ${ }^{1}$ Department of Agricultural Biotechnology, Seoul National University, Seoul 151-921, Korea \\ ${ }^{2}$ Department of Plant Pathology, University of Arkansas, Fayetteville, AR 72701, USA \\ (Received on January 25, 2010; Accepted on May 15, 2010)
}

Early nematode development and subcellular responses in resistant soybean lines PI 88788 and PI 437654 infected with races 3 (R3) and 14 (R14) of soybean cyst nematode (SCN), Heterodera glycines Ichinohe, were compared. SCN R14 nematodes penetrated and developed significantly more than $\mathrm{R3}$ at 5-6 days after inoculation. Both races also penetrated and developed more in PI 88788 than in PI 437654. Syncytia, characterized by cell wall dissolution and cellular hypertrophy, were developed more in PI 88788 than in PI 437654 and more by $\mathrm{R} 14$ than R3, for which less necrotic responses occurred in the former than the latter. This suggests that the latter two may be more resistant and less virulent than the former two, respectively. A common structural feature found in each of PI 437654 and PI 88788 in relation to $\mathrm{SCN}$-resistance was the formation of prominent cell wall appositions and nuclear degeneration prior to cytoplasmic degradation in syncytial cells, respectively. Necrosis and cell wall apposition are types of hypersensitive responses occurring at early stages of the nematode infection so that these structural modifications indicate the inhibition of initial syncytial development related to the early nematode development. As soybean cultivars and lines with identical or similar genotypes have the same types of structural features related to SCN-resistance, the structural modifications induced by $\mathrm{SCN}$ infection may result from the expression of inheritable resistance genes, of which the information can be used for breeding soybean cultivars and lines specifically resistant to SCN races.

Keywords : resistance, soybean, soybean cyst nematode, subcellular responses, syncytium

Soybean is a very important crop globally because it is growing in vast geographical areas worldwide (Riggs, 2004). The soybean cyst nematode (SCN), Heterodera glycines Ichinohe, occurring in most countries worldwide, is one of the most serious pests in its production (Wrather et al.,

\footnotetext{
*Corresponding author.

Phone) +82-2-880-4675, FAX) +82-2-873-2317

E-mail)yhokim@snu.ac.kr
}

2001). Major control tactics for managing SCN is the use of resistant soybean cultivars, which is the primary goal of soybean breeding programs (Shannon et al., 2004).

Since the first cultivar resistant to SCN, cv. Pickett, was developed and released in the USA (Brim and Ross, 1966), a variety of productive soybean cultivars resistant to SCN have been developed to cope with the arise of new SCN populations reproducible on the resistant cultivars previously developed. This resulted in diversification of virulence phenotypes (races) to soybean differentials (Riggs and Schmitt, 1988). Thus, SCN field populations should be identified at the race level and characterized in relation to their parasitism on soybean for the breeding of SCNresistant soybean cultivars and lines and their effective use for the control.

SCN induces syncytia in soybean roots as feeding sites and the syncytial development is directly related to the nematode growth (Kim et al., 1999). In susceptible soybean cultivars, the syncytia develop continuously until the late stages of infection, while they degenerate early in resistant soybeans (Kim et al., 1987). There are different structural features in relation to syncytial degeneration in different resistant soybean cultivars infected with $\mathrm{SCN}$ race 3, which is suggested to be a reflection of resistant genes (Kim et al., 1987). SCN is host specific that infects relatively few plant species beyond soybean (Hussey and Grundler, 1998). Also SCN is race-specifically virulent to the genotypes of soybean related to susceptible differentials (Shannon et al., 2004). These aspects indicate that characterization of multiple soybean cultivar (line) - SCN race relationships is needed to secure the cytological responses to be related to the genetics of the host-parasite interactions. Therefore, the objectives of this study are to examine structural modifications of the root tissues in resistant soybean lines with different genotypes infected with different SCN races.

\section{Materials and Methods}

Plants and inocula. In this study, SCN races 3 (R3) and 14 (R14) and soybean lines PI 88788 and PI 437654, totally 4 combinations, were used. The two cultivars are resistant to 
both races (Shannon et al., 2004). SCN R3 and R14 reared in a greenhouse on cvs. Lee and Pickett, respectively, were used. Cysts were harvested and crushed to release eggs. The eggs were placed on Baermann funnels for 3 days to allow the eggs to hatch to second-stage juveniles (J2). Seeds of PI 88788 and PI 437654 were germinated in vermiculite and seedlings in the cotyledon stage were transplanted to sterilized river sand in $7.5-\mathrm{cm}-\mathrm{d}$ clay pots. Two days after transplanting, approximately 1,000 J2 of SCN were added to the rhizosphere of each plant growing in a greenhouse at $23-28^{\circ} \mathrm{C}$. One day after inoculation, roots were carefully removed from the sand, rinsed in tap water to remove nematodes, and were transplanted into fresh sterilized soil to synchronize the nematode penetration time.

Examination of nematode penetration and growth. Five days after transplanting (5-6 days after inoculation), roots were washed free of sand, fixed with FAA (formalin-acetic acid-alcohol) (formalin:glacial acetic acid:95\% ethanol: distilled water $=2: 1: 10: 7$ ) overnight. The fixed roots were cleared in $2 \%$ sodium hypochlorite for $10 \mathrm{~min}$ and stained with $0.07 \%$ bromophenol blue in $50 \%$ ethanol for $8 \mathrm{~h}$, and rinsed in 50\% ethanol (Kim et al., 1986). The number of nematodes in infection sites in root tissues was counted using a stereomicroscope. Each soybean line was replicated five times. Also the growth status of the nematodes on the infection sites was examined under a compound light microscope. The infecting nematodes were divided into 2 types based on the nematode development (shape of the nematode body) in the disease cycle of SCN (Agrios, 2005): 1) undeveloped or dead nematodes that were slender with pointed tail; 2) developed nematodes that were swollen into sausage shapes.

Light and electron microscopy. Five days after transplanting (5-6 days after inoculation), whole roots were washed free of sand, fixed with Karnovsky's fixative in $0.05 \mathrm{M}$ cacodylate buffer ( $\mathrm{pH} 7.0$ ) for 2 hours, and postfixed in $1 \%$ osmium tetroxide in the same buffer for 2 hours. And then root samples were rinsed in distilled water and dehydrated in an ethanol series, and embedded in Spurr's epoxy resin (Spurr, 1969). Darkly stained nematodes in root segments could be seen through the embedding resin. Semi-thin sections (1 $\mathrm{mm}$ in thickness) were cut with a glass knife on an ultramicrotome (MT-X, RMC, Tucson, AZ, USA) to locate the infection site of the nematode, and then thin sections (80-90 nm thick) were cut with a diamond knife. Semi-thin sections were stained with $1 \%$ toluidine blue $\mathrm{O}$, and observed under a compound light microscope. The thin sections were examined under a JEM1010 transmission electron microscope (JEOL, Ltd.,
Tokyo, Japan) at an accelerating voltage of $80 \mathrm{kV}$.

\section{Results}

Nematode penetration and development. When nematodes in soybean root tissues were examined 5 to 6 days after inoculation, SCN R14 nematodes penetrated and developed significantly more than $\mathrm{R} 3$, and both races appeared to be grown more in PI 88788 than in PI 437654 (Table 1). Extremes were shown in PI 88788 with only $12.0 \%$ of infecting R14 nematodes undeveloped, but in PI 437654 with most (80.9\%) of R3 nematodes undeveloped.

Light microscopy. In the 10 to 12 specimens that were examined by light microscopy, the cytological responses

Table 1. Nematode penetration and development in resistant soybean lines at 5-6 days after inoculation with second-stage juveniles (J2) of soybean cyst nematode $(\mathrm{SCN})$ races

\begin{tabular}{|c|c|c|c|}
\hline $\begin{array}{l}\text { Soybean } \\
\text { Line }\end{array}$ & $\mathrm{SCN}$ race $^{\mathrm{a}}$ & $\begin{array}{l}\text { No. of } \\
\mathrm{J} 2 \text { penetrated per } \\
\text { root system }\end{array}$ & $\begin{array}{c}\% \text { of } \\
\text { adeveloped or } \\
\text { dead } \mathrm{J} 2\end{array}$ \\
\hline \multirow[t]{2}{*}{ PI 88788} & Race 3 & $174 \mathrm{Y}^{\mathrm{b}}$ & $39.7 Y$ \\
\hline & Race 14 & $249 X$ & $12.0 \mathrm{Z}$ \\
\hline \multirow[t]{2}{*}{ PI 437654} & Race 3 & $115 Z$ & $80.9 \mathrm{X}$ \\
\hline & Race 14 & $165 \mathrm{Y}$ & $46.7 \mathrm{Y}$ \\
\hline
\end{tabular}

${ }^{a}$ About 1,000 second-stage juveniles (J2) were inoculated to the rhizosphere of each plant.

${ }^{\mathrm{b}}$ Means of 5 replications with the same letters in each column are not significantly different at $P=0.05$ by Duncan's multiple range test (DMRT)

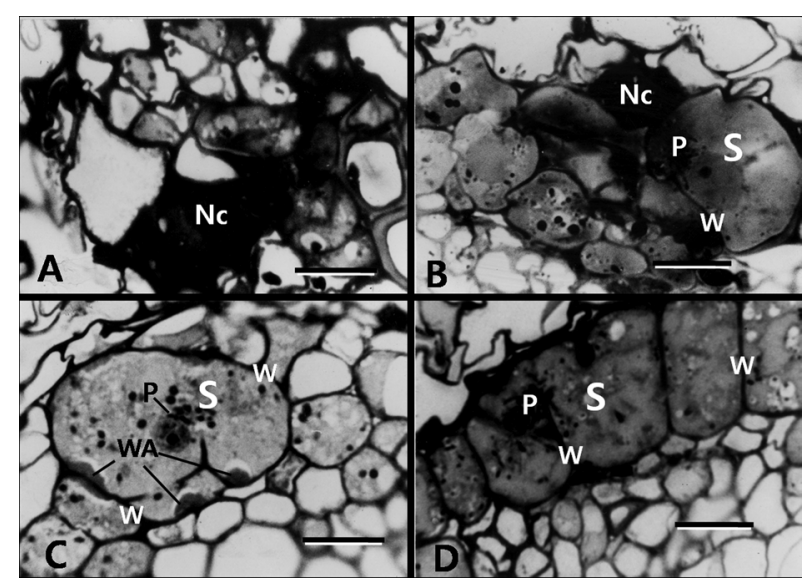

Fig. 1. Light micrographs of resistant soybean lines (A, C: PI 437654; B, D: PI 88788) infected with soybean cyst nematode races (A, B: race 3; C, D: race 14) at 5-6 days after inoculation, showing the formation of initial syncytia $(S)$ characterized by hypertrophied cells with dense cytoplasm, formation of necroses (Nc) and cell wall appositions (WA) on syncytial cell wall (W). $\mathrm{P}=$ plastids, Bars $=20 \mu \mathrm{m}$. 
varied within a soybean line-SCN race combination. However, the most frequent cytological modifications are as follows: 1) extensive necrosis at the nematode infection site with no obvious syncytium formation ( 8 out of 10 specimens) observed in PI 437654 infected with R3 (Fig. 1A), 2) syncytium formation with dense cytoplasm with necrosis around syncytial cells (7 out of 12) in PI 88788 with R3 (Fig. 1B), 3) syncytium formation with prominent calloselike cell wall appositions on inner syncytial walls (7 out of 11) in PI 437654 with R14 (Fig. 1C), and 4) syncytium formation with little or no necrosis or cell wall appositions (9 out of 11) in PI 88788 with R14 (Fig. 1D). Syncytial cells were more enlarged in PI 88788 than PI 437654 and more developed by the infection of R14 than R3.

Electron microscopy. In electron microscopy, characteristics of structural modifications in soybean lines infected with $\mathrm{SCN}$ races were similar to those viewed in the above light microscopy (Fig. 2). Except in the PI 437654-R3 combination (Fig. 2A), infected cells (indicated by feeding tubes in the cytoplasm), were hypertrophied with dense cytoplasm, indicating the formation of initial syncytial cells (Fig. 2B-D). Less developed syncytial cells were formed in PI 437654 than PI 88788 which had prominent cellular hyperptrophy, large cell wall perforations, and greatly increased plastids (Fig. 2B, D). However, cell wall appositions were rarely observed on the syncytial cells formed in

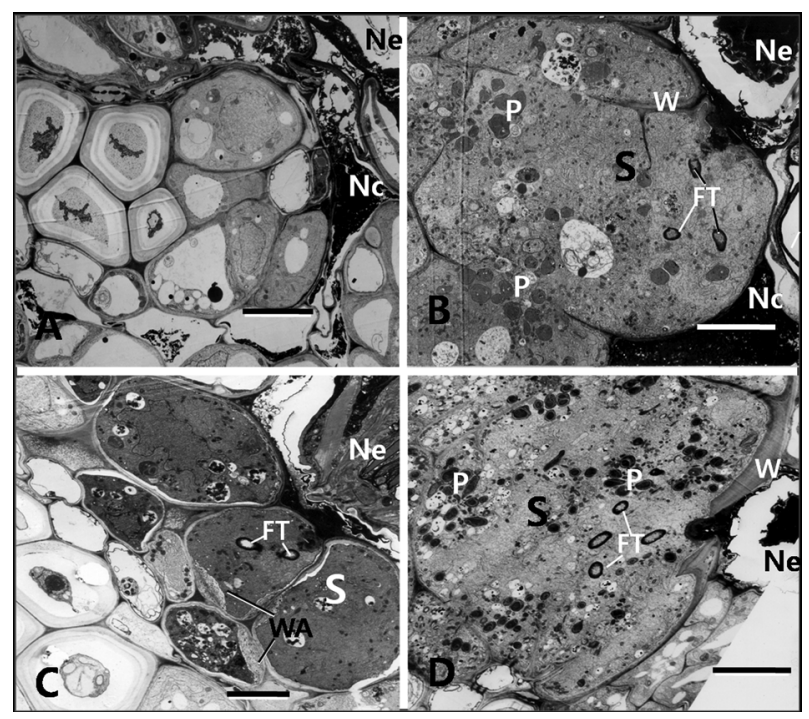

Fig. 2. Electron micrographs of infection sites in resistant soybean lines (A, C: PI 437654; B, D: PI 88788) infected with soybean cyst nematode races (A, B: race 3; C, D: race 14) at 5-6 days after inoculation, showing the formation of syncytia (S) containing dense cytoplasm, feeding tubes (FT), proliferated plastids (P), and cell wall appositions (WA) on syncytial cell walls (W). Necroses (Nc) were prominently formed adjacent to the infecting nematode $(\mathrm{Ne})$ in (A) and (B). Bars $=10 \mu \mathrm{m}$.

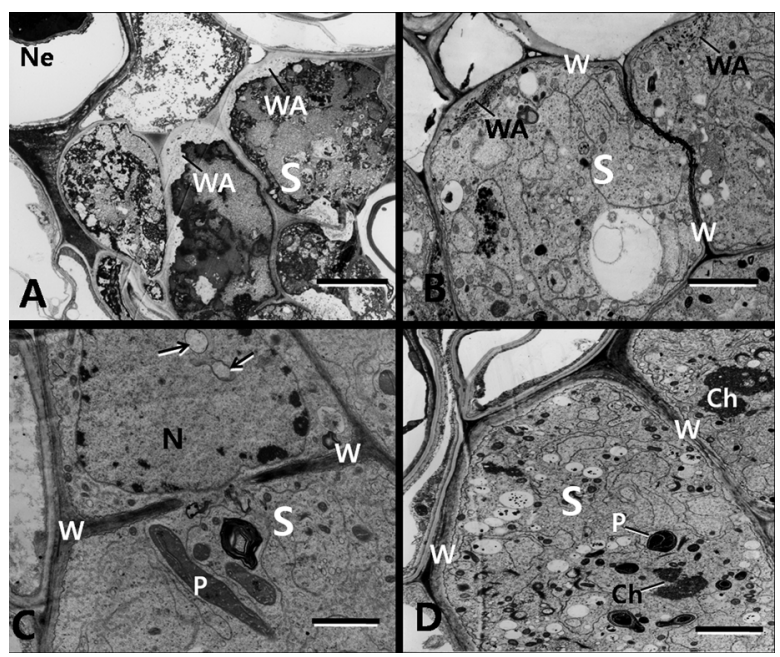

Fig. 3. Electron micrographs of common structural modifications in syncytial cells (S) (related to resistance mechanisms) found in resistant soybean lines (A, B: PI 437654; C, D: PI 88788) infected with soybean cyst nematode races (A, C: race $3 ; \mathrm{B}, \mathrm{D}$ : race 14$)$, showing the formation of cell wall appositions (WA) on syncytial walls (W) in A and B and nuclear degeneration indicated by nuclear perforations (arrows) (C) and chromatin-like materials (Ch) scattered in syncytial cytoplasm (D). Note intact syncytial cytoplasm of $\mathrm{C}$ and $\mathrm{D}$. $\mathrm{Ne}=$ nematode, $\mathrm{P}=$ plastids, Bars $=5 \mu \mathrm{m}$.

\section{PI 88788.}

The structural features common to each soybean line infected with both SCN races were shown cell wall appositions on inner syncytial cell wall in PI 437654 (Fig. 3A, B) and nuclear degeneration indicated by nuclear perforation and chromatin-like materials scattered in syncytial cytoplasm in PI 88788 (Fig. 3C, D). Except in PI 437654 with R3, prominent degenerations of syncytial cytoplasm were not noted in both soybean lines infected with both R3 and R14. The above structure features found in one soybean line were not observed in the other soybean line by electron microscopy.

Prominent necrotic responses were also found in electron microscopy of both soybean lines infected with SCN R3 (Fig. 4). When PI 437654 was penetrated by R3, necrosis occurred mostly in syncytial cells invaded by the nematode accompanying prominent cell wall appositions formed on the inner syncytial cell wall (Fig. 4A) and necrosis was also formed around the syncytial cell wall (Fig. 4B), both of which might result from intracellular necrotic responses of the soybean line to the nematode infection. In PI 88788 infected with R3, on the other hand, most necrotic responses started from the outside of the cells infected with the nematode, extending through the middle lamellae, after which necrotic materials were infiltrated into syncytial cells via diffusion and vesicular invagination (Fig. 4C-D). Finally the whole syncytial cells were necrotized with no cell 


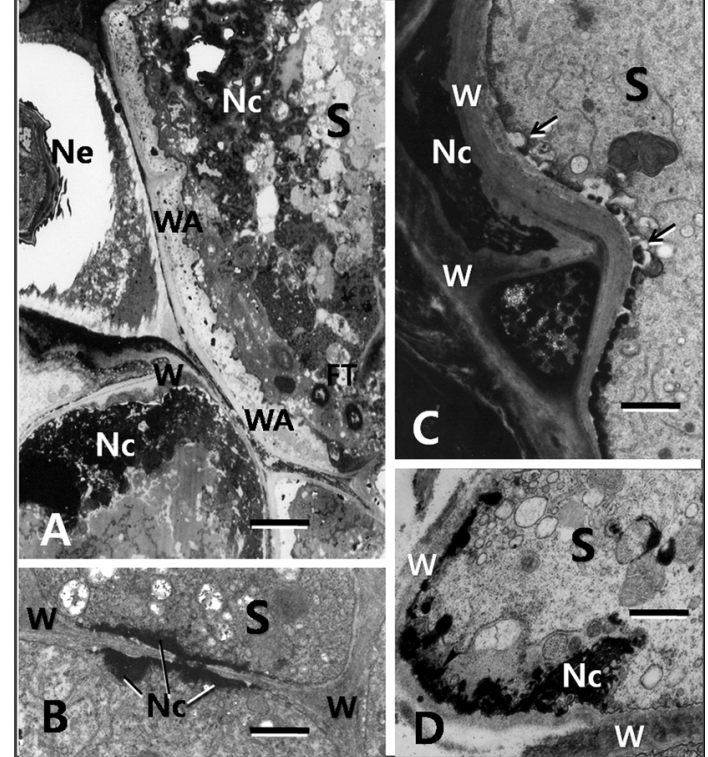

Fig. 4. Electron micrographs of necrotic responses in resistant soybean lines (A, B: PI 437654; C, D: PI 88788) to the infection of soybean cyst nematode race 3 , showing the formation of necrosis $(\mathrm{Nc})$ within syncytial cells $(\mathrm{S})$ (intracellular necrotic responses) (A, B) and in middle lamellae (intercellular necrotic responses) (C). Intercellular necroses appear to spread into syncytial cytoplasm via invagination (C) or diffusion (D). $\mathrm{Ne}=$ nematode, $\mathrm{WA}=$ cell wall apposition. $\mathrm{Bars}=10 \mu \mathrm{m}(\mathrm{A})$ and 5 $\mu \mathrm{m}(\mathrm{B}, \mathrm{C}, \mathrm{D})$.

wall appositions in and around the necrotic cells (data not shown), which indicate their necrosis might result from intercellular necrotic responses of the soybean line to the nematode infection.

\section{Discussion}

Cyst nematodes modify selected plant root cells into complex feeding sites, syncytia, for their growth and they are absolutely dependent on the formation of these feeding sites to start and continue their parasitism (Davis and Michum, 2005). Our study also shows that the percentages of dead and undeveloped nematode juveniles were higher in PI 437654 and by SCN R3 infection than in PI 88788 and by R14 infection, respectively. The former soybean line and SCN race are known to be more resistant to SCN races and less virulent to soybean cultivars and lines than the latter ones (Kim et al., 1999; Shannon et al., 2004).

Light and electron microscopy in our study revealed that structural features of the infected root cells also reflected the phenomena mentioned above, showing that necrotic responses and/or cell wall appositions were prominent in PI 437654 infected with R3. Necrosis occurred more frequently in PI 437654 and by R3 (unpublished data).
Necrosis and cell wall appositions may be types of hypersensitive responses occurring at the beginning stages of infection (Agrios, 2005). These early resistance responses may block the initial stages of infection by inhibiting the formation of the feeding sites (syncytia) at the early inflectional stages. However, in PI 88788 especially infected with SCN R14, no definite resistance responses were found with developed syncytia at the initial stages of infection, supporting the initial nematode growth. However, chromatinlike materials were scattered in the syncytial cytoplasm of PI 88788 infected with R14, which may be an indication of nuclear degeneration leading consequently to syncytial degeneration (Kim et al., 1987). In this soybean line, the infecting nematodes may have even more chances for growth and maturity at low inoculum conditions, in which plant resistance to cyst nematodes is not expressed (Kim et al., 1986; O'Brien and Fisher, 1978). This render the soybean line PI 88788 to be even susceptible to other SCN races (race 1 and race 4) (Shannon et al., 2004).

Necrosis was formed in the soybean lines much more by SCN R3 than by R14 in our study. In the comparison of these two SCN races for syncytial formation in relation to the reproduction of the nematodes, Kim et al. (1999) suggest R14 may have more aggressive feeding activity, producing more females and eggs per cyst than R3, but depleting syncytial cytoplasm rapidly to inhibit the final nematode body growth at the later stages of the nematode infection. This aggressiveness of R14 may be effective in the syncytial development at the early stages of infection by suppressing necrotic resistance responses of the soybean root cells and tissues, positively affecting the nematode growth as shown in our study. The necrotic responses occurring in the soybean lines by R3 infection differed somewhat in their initiation between PI437654 (intracellular) and PI 88788 (intercellular), which may be related to differences of their resistance levels: Necrosis might be formed later after initial syncytial development in the less resistant soybean line PI 88788.

In previous studies (Kim et al., 1987; Riggs et al., 1973), the formation of necrosis and cell wall appositions and nuclear degeneration are suggested to be resistance mechanisms of soybean cultivars to SCN. In their studies, necrosis and cell wall appositions govern the resistance of soybean cultivars Peking and Forrest that have the identical resistance responses to SCN races (Kim and Riggs, 1992). PI 88788 was used to develop cv. Bedford (Hartwig and Epps, 1978) that nuclear degeneration prior to syncytial degeneration as resistance mechanism to SCN like its parent (Kim et al., 1987). Soybean cultivar Hartwig was developed from the PI 437654 (Anand, 1992; Anand et al., 1985 ) and formed necrosis and prominent cell wall appositions in responses to $\mathrm{SCN}$ infection (unpublished data). 
All of these aspects mentioned above suggest that the structural modifications induced by the SCN infection in the resistance soybeans may be inheritable and related to the expression of specific resistance genes. Therefore, the results of our study may provide information useful for the development and screening of soybean lines and cultivars resistant to SCN races.

\section{References}

Agrios, G N. 2005. Plant Pathology, Fifth edition. Academic Press, New York.

Anand, S. C. 1992. Registration of Hartwig soybean. Crop Sci. 32:1069-1070.

Anand, S. C., Wrather, J. A. and Shumway, C. R. 1985. Soybean genotypes with resistance to races of soybean cyst nematode. Crop. Sci. 25: 1073-1075.

Brim, C. A. and Ross, J. P. 1966. Registration of Pickett soybeans. Crop Sci. 6: 305.

Davis, E. L. and Mitchum, M. G. 2005. Nematodes, sophisticated parasites of legumes. Plant Physiol. 137:1182-1188.

Hartwig, E. E. and Epps, J. M. 1978. Registration of Bedford soybeans. Crop Sci. 18:915.

Hussey, R. S. and Grundler, F. M. 1998. Nematode parasitism of plants. In: Physiology and biochemistry of free-living and plant parasitic nematodes, ed. by R. N. Perry and J. Wright, pp. 213-243. CAB International Press, Oxford.

Kim, K. S. and Riggs, R. D. 1992. Cytopathological reactions of resistant soybean plants to nematode invasion. In: Biology and management of the soybean cyst nematode, ed. by R. D. Riggs and J. A. Wrather, pp. 157-168. APS Press, St. Paul, MN, USA.

Kim, Y. H., Riggs, R. D. and Kim, K. S. 1986. A mechanism of density-dependent population changes in Heterodera glycines. Korean J. Plant Pathol. 2:199-206.

Kim, Y. H., Riggs, R. D. and Kim, K. S. 1987. Structural changes associated with resistance of soybean to Heterodera glycines. J. Nematol. 19:177-187.

Kim, Y. H., Riggs, R. D. and Kim, K. S. 1999. Heterodera glycines-induced syncytium structures related to the nematode growth and reproduction in susceptible soybean cultivars. Plant Pathol. J. 15:1-7.

O'Brien, P. C. and Fisher, J. M. 1978. Studies on the mechanism of resistance of wheat to Heterodera avenae. Nematologica 24:463-471.

Riggs, R. D. 2004. History and distribution. In: Biology and management of soybean cyst nematode, second edition, ed. by D. P. Schmitt, J. A. Wrather and R. D. Riggs, pp. 9-39. Schmitt \& Associates of Marceline, Marceline, Missouri, USA. 262 pp.

Riggs, R. D., Kim, K. S. and Gipson, I. 1973. Ultrastructural changes in Peking soybeans infected with Heterodera glycines. Phytopathology 63:76-84.

Riggs, R. D. and Schmitt, D. P. 1988. Complete characterization of the race scheme for Heterodera glycines. J. Nematol. 20: 392-395.

Shannon, J. G., Arelli, P. R. and Young, L. D. 2004. Breeding for resistance and tolerance. In: Biology and management of soybean cyst nematode, second edition, ed. by D. P. Schmitt, J. A. Wrather and R. D. Riggs, pp. 155-180. Schmitt \& Associates of Marceline, Marceline, Missouri, USA. 262 pp.

Spurr, A. R. 1969. A low viscosity epoxy resin embedding medium for electron microscopy. J. Ultrastructr. Res. 26:3143.

Wrather, J. A., Anderson, T. R., Arsyad, D. M., Tan, Y., Ploper, L. D., Porta-Puglia, A., Ram, H. H. and Yorinori, J. T. 2001. Soybean disease loss estimates for the top ten soybean producing countries in 1998. Can. J. Plant Pathol. 23:115-121. 